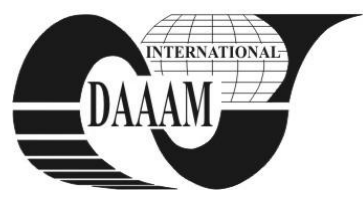

Annals of DAAAM for 2011 \& Proceedings of the 22nd International DAAAM Symposium, Volume 22, No. 1, ISSN 1726-9679 ISBN 978-3-901509-83-4, Editor B. Katalinic, Published by DAAAM International, Vienna, Austria, EU, 2011 Make Harmony between Technology and Nature, and Your Mind will Fly Free as a Bird

\title{
QUADRATURE INDUCTANCE IDENTIFICATION USING THE IMPROVE FREQUENCY ANALYSIS
}

\author{
VESELY, I[vo]; SIR, M[ichal] \& ZAMECNIK, D[usan]
}

\begin{abstract}
This paper describes online method of synchronous motor parameter identification (online improved frequency analysis). If stator resistance is used to refine results the final result of identification is more accurate.In our case motor has unstable parameters which are changed by up to 50 percent. In paper method improved frekvency analysis is used to identify variable inductance which is dependent on the current.
\end{abstract}

Key words: permanent magnet synchronous motor, parameter identification, stator resistance, quadrature inductance

\section{INTRODUCTION}

Nowadays, permanent magnet synchronous motors are widely used in many industrial applications also in domestic electrical appliances. These motors create magnetic flux using permanent magnet instead of the excitation winding. And as compared with asynchronous motors, these motors have very simple structure, operate with greater power factor and achieve a smaller size while maintaining the same performance. However, if we want to use these engines the most effectively, we must join to them quality control (Vas, 1993). One of the indispensable information for the control algorithm is the knowledge of the actual motor parameters (Ghomi \& Sarem, 2007). Methods to obtain these parameters are several species and one of them is the injection signal method (Sungmin, 2010). The following paper describes one of these methods (improve frequency analysis) (Söderström \& Stoica, 1989) and its principle, methods of calculating and identification of variable induction.

\section{SYNCHRONOUS MOTOR WITH VARIABLE QUADRATURE INDUCTANCE}

In our case permanent magnet synchronous motor is characterized by several attributes, which complicate the control of motor. One of these attributes is variable quadrature inductance due to motor design and used materials. This inductance is dependent on the current which maxumim change is up to 50 percent (Fig. 1).

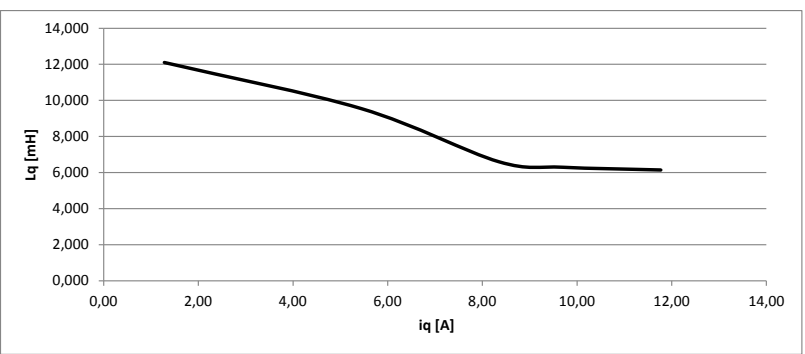

Fig. 1. Title of figure, left justified, subsequent text indented

Correct value of inductance is necesary for decoupling. Value of the feedback is calculated from this value and the measured currents. Control accuracy depends on the accuracy of this value.

\section{ONLINE IMPROVED FREQUENCY ANALYSIS}

The method uses knowledge of synchronous motor schema in d-q coordinates (Neborák, 2002) and it is based on mutual signals correlation. The equivalent schema of synchronous motor can be divided into two parts. The first is associated with the d-coordinate and the second one is associated with qcoordinate. In our case, we aim the q-part not to affect the identification when we identify d-parameters and vice versa. The motor control has to include decoupling which is necessary to meet this condition. As d-part and q-part are nearly identical, the identification of inductance $L_{d}\left(L_{q}\right)$ (further identified as $L_{x}$ ) is similar. The identification harmonic signal is connected to the input of identified part, in our case $U_{q}$. If the control includes decoupling a first order system is created.

$$
F(p)=\frac{\frac{1}{R_{S}}}{\frac{L_{x}}{R_{S}} p+1}
$$

We know that the input signal $U_{q}$ is

$$
u(t)=A \sin (\omega t)
$$

The following signal is the output, after stabilization of the transitional process

$$
y(t)=B \sin (\omega t+\varphi)
$$

Where B is amplitude of output signal

$$
\begin{aligned}
& B=A|G(j \omega)| \\
& \varphi=\arg G(j \omega)
\end{aligned}
$$

During the identification we need to get two values which are needed for the calculation (Fig. 2).

One of them is obtained by the output signal $y(t)$ multiplied by $\sin (\omega t)$ and the result is integrated over one or more periods

$$
\begin{aligned}
& y_{s}(T)=\int_{0}^{T} y(t) \sin (\omega t) d t=\int_{0}^{T} B \sin (\omega t+\varphi) \sin (\omega t) d t+ \\
& \int_{0}^{T} e(t) \sin (\omega t) d t \cong \frac{B T}{2} \cos (\varphi)
\end{aligned}
$$

The second value is obtained almost in the same way. Signal $y(t)$ is multiplied by $\cos (\varphi)$ and also the result is integrated over one period or more periods this time

$y_{c}(T)=\int_{0}^{T} y(t) \cos (\omega t) d t=\int_{0}^{T} B \sin (\omega t+\varphi) \cos (\omega t) d t+$
$\int_{0}^{T} e(t) \cos (\omega t) d t \cong \frac{B T}{2} \sin (\varphi)$

If we use equations (4),(5) we can write

$$
\begin{aligned}
& y_{S}(T)=\frac{A T}{2} \mathfrak{R}[G(j \omega)] \\
& y_{c}(T)=\frac{A T}{2} \mathfrak{J}[G(j \omega)]
\end{aligned}
$$


Where $\mathfrak{R}[G(j \omega)]$ and $\mathfrak{J}[G(j \omega)]$ are real and the imaginary part of the transfer function of our first order system.

It is appropriate to connect harmonic signal to the engine with such a frequency which gives approximately the same amplitude of $y_{s}$ and $y_{c}$ to achieve good accuracy. It can be done by iterative selection of $\omega$, which will ensure the same level of amplitude. If we connect such harmonic signal to the engine, that values $y_{s}$ and $y_{c}$ are at least the same order, then method will have got better accuracy.

We need the transfer function of our first order system for identification. The transfer function for identification of $R_{S}$ is $F(j \omega)=\frac{\frac{1}{R_{S}}}{\frac{L_{q}}{R_{S}} j \omega+1}$. First we need to get real and imaginary parts of transfer function.

$$
\begin{aligned}
& \Re[G(j \omega)]=\frac{\frac{1}{R_{S}}}{1+\omega^{2}\left(\frac{L_{q}}{R_{S}}\right)^{2}} \\
& \mathfrak{J}[G(j \omega)]=\frac{-\omega \frac{L_{q}}{R_{S}^{2}}}{1+\omega^{2}\left(\frac{L_{q}}{R_{S}}\right)^{2}}
\end{aligned}
$$

Then the real and imaginary parts are substituted into equations (8) and (9).

And now all variables are known and quadrature inductance $L_{q}$ and stator resistance $R_{S}$ can be calculated.

$$
\begin{gathered}
L_{q}=\sqrt{\frac{A T R_{S}-2 y_{s} R_{S}^{2}}{2 y_{s} \omega^{2}}} \\
R_{S}=\frac{A T y_{s}}{2\left(y_{s}^{2}+y_{c}^{2}\right)}
\end{gathered}
$$

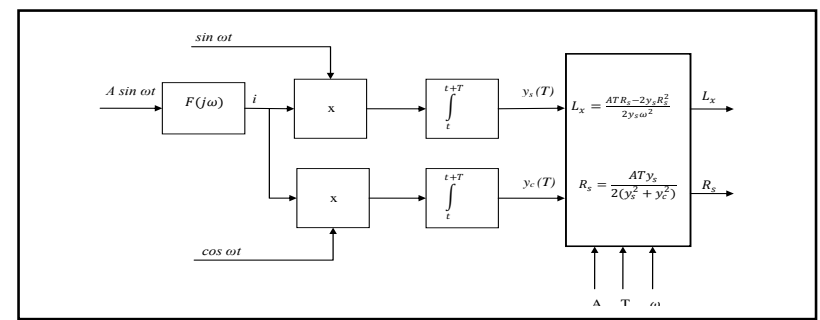

Fig. 2. Improve frequency anylysis

\section{EFFECT OF CALCULATION METHOD ON THE ACCURACY OF IDENTIFICATION}

One of the many things, which affect the accuracy of the identification, is the method of calculation. Inductance is calculated by equation (12).

Because the equation contains the stator resistance, inductance can be calculated in two ways. One way of calculating the inductance $L_{q}$ is substituting the value of the stator resistance. It is known from the initial initialization or the continuous identification by other method. The second way uses simultaneously identification of the stator resistance and quadrature inductance by improved frequency analysis, where the stator resistance is calculated by (13). The second way has better results because calculation of stator resistance compensates error which is caused by the changes of current. Current and value of identification resistence have the same trend with time delay of the resistance trend (Fig. 3).

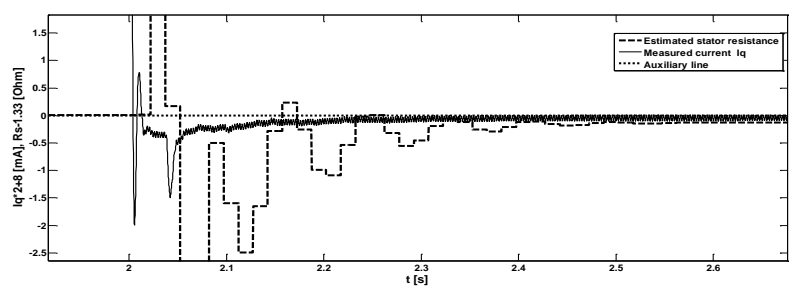

Fig. 3. The progress of current $I_{q}$ and stator resistance $R_{S}$

\section{ONLINE IDENTIFICATION}

The identification may not be always accurate at the runtime of motor. Errors arise mainly when trend of speed is changed. Identified value must be adjusted to control worked well and did not crash. Therefore, this value is limited in the decoupling block (Fig. 4). The range of limit is $\pm 0.005 \mathrm{mH}$ from the estimated value that is obtained experimentally from inicilaizace.

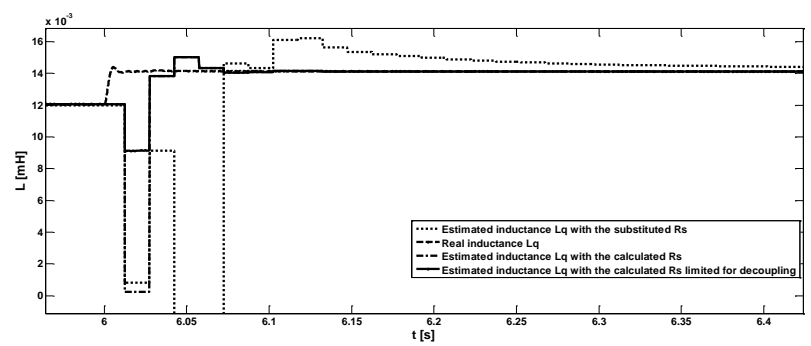

Fig. 4. The progress of inductance while trend of speed is changed

In the picture you can see the progress of inductance while trend of speed is changed. Inductance is abruptly changed due to the features of the motor. Each identification method always achieves the right result but with different time of identification.The figure shows the errors of identification incurred while the trend of speed is changed and also shows how much the identificaton result had to be limited.

\section{CONCLUSION}

The paper describes the improved frequency analysis. We modify it for use in online mode. The identification harmonic signal in the feedback must be modified and the identified variable must be modified for use in decoupling. After these modifications the method can be well used in online identification. Furthermore, the calculation of inductance was modified. The calculation of inductance uses the calculation of stator resistence. This modification increased accuracy and speed of identification, as you can see in the previous graphs. And you can identify induction while trend of speed is changed. This method has been tested withoud load of motor. Therefore, future research will focus on accuracy verifycation of motor which work with load. And apply the algorithm to real processor and tested it on the motor.

\section{ACKNOWLEDGEMENTS}

The research has been supported by Czech Science Foundation under the project 102/09/H081 "SYNERGY Mobile Sensoric Systems and Network","Supporting Research of Modern Methods and Approaches in Automation" from the Internal Grant Agency of Brno University of Technology (grant No. FEKT-S-11-6). and European Regional Development Fund under project No. CZ.1.05/2.1.00/01.0014.

\section{REFERENCES}

Ghomi, M., Sarem, Y.N. (2007). Review of synchronous generator parameters estimation and model identification. Universities Power Engineering Conference, UPEC 2007

Neborák, I. (2002). Modelováni a simulace elektrických regulovaných pohonů. Vysoká škola Báňská- technická univerzita Ostrava, Ostrava

Söderström, T.; Stoica, P. (1989). System identification. Prentice Hall International, UK

Sungmin, K. et al. (2010) Parameter independent maximum torque per ampere (MTPA) control of IPM machine based on signal injection. Applied Power Electronics Conference and Exposition (APEC), Twenty-Fifth Annual IEEE

Vas, P. Parameter Estimation, Condition Monitoring and Diagnosis of Electrical Machines. Oxford University Press 1993. ISBN 0-19-859375-9 